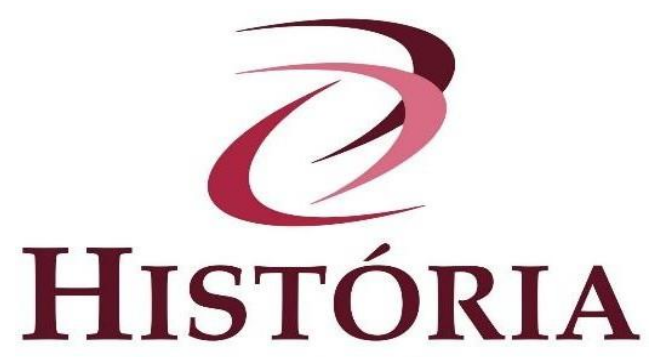

debates e tendências

\title{
Anamnese, Diagnóstico e Terapêutica: O Discurso Médico na Transferência da Capital de Goiás
}

\author{
Anamnesis, Diagnosis and Therapy: The Medical Discourse in the Transfer of \\ Goiás State Capital
}

\section{Anamnesis, Diagnóstico y Terapia: El Discurso Médico en la Transferencia de la Capital de Goiás}

Rildo Bento de Souza ${ }^{\mathrm{i}}$

Resumo: o objetivo deste artigo é analisar o discurso do médico e político Pedro Ludovico Teixeira para justificar a construção de uma nova capital no Estado de Goiás no início da década de 1930, com base em dois documentos: o Relatório de 1933, e um opúsculo com a transcrição de uma palestra de 1966. Quando assumiu o poder como Interventor no Estado, após a Revolução de 1930, Pedro Ludovico arquitetou um plano para transferir a capital, retirando-a da Cidade de Goiás, erguida no período colonial, para uma cidade construída a partir de um discurso que tinha por base a higiene e a salubridade. Para conseguir a aceitação de tal ideia, em um período de grave crise econômica, Pedro Ludovico analisou a então capital como um doente, e, ao desconstruí-la, constrói assim o seu modelo de cidade ideal. Palavras-chave: Cidade de Goiás, discurso médico, Pedro Ludovico Teixeira.

\begin{abstract}
The aim of this article is to analyze the discourse of the physician and politician Pedro Ludovico Teixeira to justify the construction of a new capital of Goiás State in the early 1930's, from two documents: the 1933 Report, and an opuscule with the transcription of a 1966 lecture. When he assumed the power as an Intervenor in the State after the 1930 Revolution, Pedro Ludovico architected a plan to transfer the capital, removing it from Goiás city, raised in the colonial period, to a city built under the aegis of hygiene and health. To achieve the acceptance of such an idea, in a period of severe economic crisis, Pedro Ludovico analyzed the upcoming capital as a sick person, and by deconstructing it, builds his model of ideal city.

Keywords: Cidade de Goiás, medical discourse, Pedro Ludovico Teixeira.

Resumen: El objetivo de este artículo es analizar el discurso del médico y político Pedro Ludovico Teixeira para justificar la construcción de una nueva capital en el Estado de Goiás a principios de la década de 1930, a partir de dos documentos: el Informe de 1933, y un opúsculo con la transcripción de una conferencia de 1966. Cuando tomó el poder como Interventor en el Estado después de la Revolución de 1930, Pedro Ludovico diseñó un plan para transferir la capital, sacando de la ciudad de Goiás, erigida en el período colonial, a una
\end{abstract}


ciudad construida bajo la égida de la higiene y la salud. Para lograr la aceptación de tal idea, en un período de grave crisis económica, Pedro Ludovico analizó la capital de entonces como a un enfermo, y de construyéndola, construye así su modelo de ciudad ideal.

Palabras-clave: Cidade de Goiás, discurso médico, Pedro Ludovico Teixeira.

\section{Introdução}

$\mathrm{O}$ artigo se propõe a analisar o discurso do médico e político vilaboense Pedro Ludovico Teixeira (1891-1979), para justificar a construção de uma nova capital no Estado de Goiás no início da década de 1930. Quando assumiu o poder como Interventor no Estado após a Revolução de 1930, Pedro Ludovico arquitetou um plano para transferir a capital, retirando-a da Cidade de Goiás, que remetia ao período colonial, para uma cidade construída a partir de um discurso que tinha por base a higiene e a salubridade. Para conseguir a aceitação de tal ideia, Pedro Ludovico analisou a então capital como a um doente, e ao desconstruí-la, constrói assim o seu modelo de cidade ideal.

A análise partirá de dois documentos, quais sejam, Relatório apresentado ao Exmo. Snr. Dr. Getúlio Vargas, d. d. Chefe do Governo Provisório, e ao povo goiano, pelo dr. Pedro Ludovico Teixeira, Interventor Federal neste Estado, e o opúsculo Como e porque construí Goiânia. O primeiro enfeixa o balanço do governo entre 1930 a 1933, dividido em onze capítulos, cujo mais importante para a análise proposta neste artigo é o nono, intitulado Mudança da Capital. O segundo, por sua vez, trata da transcrição de uma palestra dada pelo então Senador Pedro Ludovico ao Departamento de Geografia e História da Universidade Federal de Goiás em 1966.

Pedro Ludovico nasceu em 1891, na Cidade de Goiás, então capital do Estado, onde residiu até 1910, quando se dirigiu ao Rio de Janeiro com o objetivo de estudar engenharia. Na então Capital Federal, mudou de ideia e dedicou-se à medicina, onde se formou em 1916. Ao retornar ao seu Estado natal, passou um período em Bela Vista, logo depois em Trindade e, finalmente, se estabeleceu em Rio Verde, no sudoeste goiano, em 1917. No ano seguinte, casou-se com Gercina Borges Teixeira, filha do coronel e então senador estadual Antônio Martins Borges, que se opunha a situação política goiana, que era comandada pela família Caiado. De 1917 a 1930, antes de assumir a Interventoria Federal após a Revolução de 1930, Pedro Ludovico dedicou-se à medicina e ao jornalismo, já que fora editor do Jornal "O Sudoeste", onde combatia seus adversários políticos.

Nas eleições de 1930, Pedro Ludovico viu fracassar a sua tentativa de ingressar à Câmara Federal, embora tenha sido o mais votado entre os candidatos da oposição. Em 
outubro, com a vitória da Aliança Liberal, da qual participara dos combates em Goiás, ascendeu à chefia do executivo estadual e permaneceu quinze anos ininterruptos no poder, ora como Interventor ora como Governador. Nesse período consolidou a sua principal bandeira política: a construção de Goiânia, que, em 1937, tornou-se a nova capital do Estado, em detrimento da Cidade de Goiás. Ademais, foi Senador, Governador e novamente Senador até 1968, quando, por meio do Ato Institucional n. 5 (AI-5), teve os seus direitos políticos cassados. Durante o período de ostracismo político, lançou a sua autobiografia em 1973, ficou viúvo em 1976 e morreu devido a problemas cardíacos em sua residência em 16 de agosto de 1979.

\section{O atraso como doença e o progresso como remédio}

No primeiro capítulo do seu estudo sobre Goiânia, Wilton de Araújo Medeiros argumenta que, antes de existir, Goiânia foi pensada, ou, antes de tudo, sonhada; é o que ele denominou de "Sonho de Pedro Ludovico". Para que esse sonho se tornasse realidade, o Interventor precisou construir ferramentas que se transformassem em conceitos, "pois, somente por meio da elaboração de conceitos se poderia ter uma cidade concreta". Ademais, “é muito marcante como o Interventor do Estado é também um interventor da vida e da história para dar conta de realizar o seu sonho". Afinado aos propósitos da nação pósRevolução de 1930, Pedro Ludovico se articulou com outras pessoas que comungavam desse mesmo desejo e construiu argumentação que, inicialmente, perpassou a história e a ciência (MEDEIROS, 2010, p. 37).

E o principal argumento que sustentou a ideia da construção de Goiânia foi o do “progresso" (CHAUL, 2010, p. 234; CHAUL, 1988, p. 166; MACHADO, 1990, p. 153; SILVA, 2002, p. 129). Na Introdução do Relatório de 1933, Pedro Ludovico ressaltou que, no constante combate ao marasmo, procurava infiltrar "no seio do povo e das administrações as idéas de progresso" (TEIXEIRA, 1933, p. 05). Tais ideias convergiam para o fato de que o Estado somente conseguiria se desenvolver com a construção de uma nova capital. Esse discurso de "progresso"perpassou toda a trajetória política de Pedro Ludovico. Em 1978, por exemplo, quando concedeu sua última entrevista, foi perguntado sobre como era Goiás em 1930, a resposta veio clara e objetiva: "Muito atrasado. Na mesma situação de Mato Grosso e Piauí. Ele só começou a melhorar, a progredir, a se elevar, depois que mudei a capital". (TEIXEIRA, 2009, p. 194).

Como ideia e ideal, o progresso surgiu no século XVII, na Inglaterra, sendo formulado por Francis Bacon. De acordo com seus postulados, o progresso só seria 
alcançado a partir de "uma operação coerentemente planejada e dirigida" (OUTHWAITE; BOTTOMORE, 1996, p. 614). Outrossim, o termo progresso também designa "a crença de que os acontecimentos históricos se desenvolvem no sentido mais desejável, realizando um aperfeiçoamento crescente" (ABBAGNANO, 2000, p. 799). Desse modo, o progresso é, para Pedro Ludovico, "sinônimo de desenvolvimento". Por conseguinte, a Cidade de Goiás se tornou "a expressão do atraso", e Goiânia, por sua vez, "o símbolo do progresso, expressão de um Estado que rompe com seu passado e de um povo que se mostra capaz de construir seu futuro ativamente. E isso será dito por Pedro Ludovico, em diferentes oportunidades" (CAMPOS, 2002, p. 176-177).

Para Pedro Ludovico, a Cidade de Goiás, como capital, era o grande empecilho para o desenvolvimento do Estado. Porém, a proposta de criação de uma nova, dentro de um contexto de crise mundial (devido as consequências da quebra da Bolsa de Nova York em 1929), em uma das mais pobres unidades da federação, evidenciava quão difícil seria a empreitada. Luís Palacín, em seu estudo, argumenta que a mudança da capital representou, com base em uma "Revolução não-revolucionária", "uma força motriz, desestabilizadora e exigente de esforço, capaz de produzir súbitas inversões sociais". Ou seja, uma nova capital seria “uma revolução permanente, onde não houvera revolução" (PALACÍN, 1986, p. 86).

Desse modo, pressupomos que a Revolução de 1930 não seria capaz de produzir os dividendos políticos necessários para a sua perpetuação do poder, motivo pelo qual Pedro Ludovico lançou a ideia da construção de uma nova capital, com o objetivo, primeiramente, político. Caso essa ideia fosse concretizada e obtivesse êxito, seu nome seria perpetuamente lembrado.

Entretanto, Pedro Ludovico teceu discurso sobre sua ideia de que o progresso do Estado estava condicionado à mudança da capital e constituía constatação do que, muitos antes dele, já haviam observado. Isso fica evidente nos argumentos históricos e científicos que embasaram a sua justificativa para a defesa da mudança. Ou seja, desde o século XVIII, algumas vozes já se levantaram contra a Cidade de Goiás. Por um lado, Pedro Ludovico, com isso, divide os créditos pela ideia, porém, ao levar a cabo tal empresa, se projeta como alguém que teve a coragem de realizá-la; muito mais coragem do que todos os que a pensaram no passado.

Em 1966, em sua palestra na Universidade Federal de Goiás, ele parte do mesmo princípio, mas com base em outra perspectiva: "a opinião de que o atraso material de Goiás derivava, em grande parte, da inércia da velha capital não era somente nossa. Era coletiva." (TEIXEIRA, 1966, p. 15). Embora tenha afirmado que havia outros fatores responsáveis 
pelo atraso em Goiás, Pedro Ludovico destacou como o mais "flagrante" a situação da então capital: além de não conseguir impulsionar o progresso do Estado, possuía problemas crônicos como ausência de água canalizada, e rede de esgoto, além de se situar em um fundo de um vale, cercada pela Serra Dourada, em um lugar nada salubre e sadio. Tais concepções são, também, a base do Relatório de 1933, onde "Goiás é examinado como a um doente [...] Em tudo, Pedro Ludovico interfere, esquadrinha" (CAMPOS, 2002, p. 170). Desse modo, o médico e o político se entrelaçam.

\section{Anamnese}

Anamnese é a entrevista realizada entre o profissional de saúde e o paciente com o objetivo de ajudar no diagnóstico de uma doença. É nesse momento que o paciente confidencia ao médico os seus problemas e as circunstâncias em que eles ocorrem. Somente a partir daí é que, quando necessário, o médico encaminha os pedidos de exames complementares. Mas como proceder a isso com uma cidade? Como uma cidade poderá falar? Pedro Ludovico poderia se basear no seu próprio olhar em relação à cidade e chegar a um diagnóstico, entretanto, ele recorreu a outros olhares que traduziram a Cidade de Goiás em diferentes épocas.

Como se conservada in vitro, a antiga Vila Boa, ainda, mantém suas características arquitetônicas do pretérito. Cercada pela Serra Dourada, a Cidade de Goiás é cortada ao meio pelo rio Vermelho, famoso nos versos de Cora Coralina. Nos dois lados da cidade, erguem-se as ruas, becos e vielas, traçados em subidas e descidas desalinhadas. Dessa forma, a Cidade de Goiás, passado o trauma, primeiro da diminuição aurífera ao final do século XVIII e, posteriormente, da mudança da capital, conseguiu encontrar o seu sentido histórico por meio do patrimônio, que se inicia na segunda metade do século XX, com os primeiros tombamentos. O ápice desse processo ocorreu em dezembro de 2001 quando, em Helsinque, na Finlândia, a antiga capital do Estado foi inscrita na Lista do Patrimônio Histórico da Humanidade pela UNESCO. O discurso norteador do processo de tombamento foi justamente a sua arquitetura, a sua localização e a sua memória histórica. É interessante essa pequena digressão para ressaltar que são justamente esses mesmos elementos (arquitetura, localização e memória histórica) que Pedro Ludovico evocou no Relatório de 1933 e na palestra de 1966, para o seu diagnóstico sobre a doençada Cidade de Goiás.

A cidade, fundada pelo bandeirante paulista Bartolomeu Bueno da Silva, mais conhecido pela alcunha de Anhanguera, como seu pai, foi ressignificada e sofreu diversas interpretações que se adequaram ao contexto da época. De acordo com Pedro Ludovico, 
“encerrado o ciclo heróico e enganador da mineração", a "decadência da capital era evidente e constritora" (TEIXEIRA, 1933, p. 117). No sentido linear, o primeiro testemunho evocado no Relatório é o de José Vieira Couto de Magalhães (1837-1898), então Presidente da Província, que diz em 1863: "Em uma palavra - Goiaz, não só não reúne as condições necessárias para uma capital, como ainda reúne muitas para ser abandonada" (MAGALHÃES apud TEIXEIRA, 1933, p. 119). No seu discurso, ressalto os seguintes pontos:

Temos decaído desde que a industria do ouro desapareceu. Ora, a situação de Goiaz era bem escolhida quando a Província era aurífera. Hoje, porém, que está demonstrado que a criação do gado e a agricultura valem mais de que quanta mina de ouro há pela Provincia, continuar a capital aqui é condenar-nos a morrer de inanição, assim como morreu a industria que indicou a escolha deste lugar. [...] Quanto a mim, entendo que, na escolha do lugar para uma capital, se deve atender a diversas condições, que capitulo pela seguinte forma: condições higienicas, condições comerciais, condições administrativas. [...] Quanto a salubridade, não conheço, entre todos os lugares por onde tenho viajado (e não são poucos) um onde se reunam tantas molestias graves. Quasi que se pode asseverar que não existe aqui um só homem são. [...] reproduzindo uma palavra verdadeira e melancolica do finado Bispo, pode-se dizer "que aqui a vida se escoa gemendo constantemente". [...]O comercio aqui vive exclusivamente dos empregados públicos e da força de linha. Os meios de transporte são imperfeitos, a situação da cidade, encravada entre serras, faz com que sejam péssimas e de difícil transito as estradas que aqui chegam. (MAGALHÃEES apud TEIXEIRA, 1933, p. 117 a 120).

Outro testemunho ressaltado por Pedro Ludovico foi o do Presidente da Província de Goiás, Rodolfo Gustavo da Paixão (1853-1925), que, em um documento anexo à mensagem enviada, em 1891, à Assembleia Estadual, descreve um quadro desolador sobre a cidade de Goiás. Entretanto, o então Presidente não sugeriu, explicitamente, como Couto de Magalhães na citação acima, que a capital fosse transferida, porém, no seu discurso Rodolfo da Paixão ressaltou:

\begin{abstract}
A Capital de Goiaz é, sem duvida, uma daquelas cidades cujo estado sanitario, dia a dia a peior, reclama as mais prontas e enérgicas providencias. [...]Situada $[\ldots]$ sobre terreno acidentado, cercada de altos montes [...] embaraçando-lhe a regular ventilação $[\ldots]$ castigada por excessiva temperatura $[\ldots]$ com uma edificação á antiga, obedecendo, in totum, á arte colonial, que era antes a negação dos mais rudimentares princípios arquitetônicos e dos mais salutares preceitos da moderna higiene. [...] as margens do Rio Vermelho (...) despejo e lavadouro da população, não é e nem póde ser convenientemente distribuída ás casas. [...] desprovida de bom sistema de esgotos, capaz de evitar o uso prejudicialissimo das latrinas perfuradas no terreno, onde as materias fecais sem escoamento entram em rapida decomposição e exalam deleterios miasmas. [...] a decadente Vila Bôahospéda em seu seio poderosos agentes de destruição, que hão de, em breve, transforma-la em vasta Necropole, onde a morte campeie com todo o seu cortejo de horrores (PAIXÃO apud TEIXEIRA, 1933, p. 111 e 112).
\end{abstract}

Em torno desses dois testemunhos, Pedro Ludovico teceu o seu discurso desabonador, ou o seu diagnóstico, em relação à Cidade de Goiás. Talvez, se quisesse, o 
então Interventor do Estado poderia unir aos seus argumentos o fato de que, em 1830, pela primeira vez, se falou sobre a mudança da capital. Ela foi feita pelo então Presidente da Província, Miguel Lino de Morais, que queria levá-la para o norte, nas proximidades da região conhecida como Água Quente, hoje Caldas Novas (MONTEIRO, 1938, p. 03). Na palestra de 1966, no entanto, Pedro Ludovico resgatou a opinião de Lino de Morais e a juntou a Couto de Magalhães e Rodolfo da Paixão. Isso evidencia que, no decorrer de todo esse tempo, Pedro Ludovico continuou juntando argumentos de pessoas no passado para justificar a sua ideia de mudar a capital, mesmo ela já estando consolidada e amplamente aceita, como na década de 1960.

Contudo, nesse ínterim, é necessária uma pequena reflexão sobre a ausência de um documento que causou enorme furor quando foi lançado em 1916, por coincidência, mesmo ano em que Pedro Ludovico tornava-se bacharel em medicina no Rio de Janeiro: o relatório intitulado Viagem Cientifica. Em 1912, por solicitação da Inspetoria de Obras contra as Secas, órgão vinculado ao Ministério dos Negócios da Indústria, Viação e Obras Públicas, o Instituto Oswaldo Cruz organizou uma expedição chefiada pelos médicos sanitaristas Artur Neiva (1880-1943) e Belisário Pena (1868-1939), que, durante nove meses, mapeou o quadro nosológico do Norte da Bahia, sudoeste de Pernambuco, sul do Piauí e de todo o território goiano. Quatro anos depois, foi publicado o extenso relatório dessa expedição nas Memórias do Instituto Oswaldo Cruz, que descortinou para o litoral a face de um país atrasado, onde "a solidão, a miséria, o analfabetismo universal, o abandono completo dessa pobre gente, devastada moralmente pelo obscurantismo, pelas abusões e feitiçarias, e física e intelectualmente por terríveis molestias endêmicas" (NEIVA; PENA, 1999, p. 220-221). Esse relatório tornou-se o fundamento do movimento sanitarista na Primeira República e foi muito criticado pela intelectualidade goiana, principalmente nas páginas da Revista Informação Goyana, que a considerou um atentado e um desrespeito a população de Goiás (LISBOA, 2009; SANDES; CAIXETA, 2016). De acordo com Nísia Trindade Lima, o documento:

[...] não só reuniu um amplo registro fotográfico, como apresentou o relatório de viagem que, publicado em 1916, tornou-se um marco de origem do movimento pelo saneamento rural na Primeira República. Uma das referências centrais do discurso em prol do saneamento é a célebre frase do médico Miguel Pereira "O Brasil é um imenso hospital". [...] empreendeu amplo levantamento da flora, da fauna, do quadro de doenças e das condições de vida das populações locais. $\mathrm{O}$ retrato do Brasil, então esboçado, aponta a doença e não o clima ou a raça, como principal problema para o progresso das regiões. $\mathrm{O}$ atraso estava intimamente associado ao isolamento ou, para utilizar os termos do relatório, ao abandono a que eram relegadas as populações do interior do Brasil. Esse quadro era responsável pela ausência de qualquer sentimento de identidade nacional (LIMA, 
1999, p.84).

Há de se destacar que Goiás foi o único Estado percorrido de "norte a sul" pela expedição de Manguinhos, mapeando-o e descrevendo-o sob vários aspectos. Um relatório que desnudou para o Brasil as mazelas do interior, com uma população doente e desassistida pelo poder público, que recorria a uma medicina não científica para tratar os males que a afligia, poderia ser usado para fundamentar o relatório de Pedro Ludovico, de forma muito mais incisiva que as declarações de dois ex-presidentes de Província do século anterior. Porém, os “esquecimentos seletivos", na expressão de Poulot (2011), reforçam a lógica do pensamento do médico e político Pedro Ludovico em caracterizar a Cidade de Goiás como uma cidade doente e sem salvação: no relatório da expedição dos médicos de Manguinhos, a então capital não aparece como a vilã do atraso do Estado. Na sua passagem por ela, em setembro de 1912, os médicos viajantes a descreveram em todos os seus pormenores, com uma impressionante riqueza de detalhes:

\begin{abstract}
Goiaz é uma cidade regular, de construções antigas, sem arquitetura, com o tipo das velhas casas das cidades do interior de Minas. Em todo caso é uma cidade, onde já se pode viver sem muito sacrificio, tendo acomodações para tropas, sociedade bem constituida, biblioteca regular, clube recreativo e literario, alguma vida intelectual. A cidade é calçada, e as casas comerciais bem sortidas, algumas bem importantes com grandes depozitos de generos, fazendas, calçados, chapéos e objetos de armarinho. Ha muitas casas de sirios. O transporte de mercadorias é feito em larga escala por tropas, e carros de bois até Anhanguera ou Araguari, em bôa estrada com o percurso de 80 legoas. Além de varias igrejas; conta com diversos edifícios publicos[...] A população da cidade propriamente dita, cujas habitações não se prestam ao habitat do barbeiro, por serem rebocadas, caiadas ${ }^{i i}$, forradas e assoalhadas, e além disso seus habitantes bem alimentados e adistrictos já ás exijencias dos preceitos de hijiene, têm aspecto de saúde, as crianças são sadias e folgazãs. (NEIVA; PENA, 1999, p. 222).
\end{abstract}

O trecho do relato acima descortina uma Cidade de Goiás que Pedro Ludovico fez questão de esconder. Ao ressaltar os seus aspectos positivos, que surpreendeu os visitantes, tais como: o comércio, as boas estradas, a biblioteca, clubes literários (numa clara referência ao Gabinete Literário ${ }^{i i i}$ ), os edifícios públicos, as casas rebocadas e caiadas, "forradas e assoalhadas", a população bem alimentada, seguindo os preceitos higiênicos, Arthur Neiva e Belisário Pena forjaram um discurso que poderia colocar em xeque toda a argumentação de uma cidade doente urdida por Pedro Ludovico.

Pressupomos que a ausência desse importante documento no Relatório de 1933 apenas reforça os objetivos ludoviquistas. Acaso Pedro Ludovico se baseasse no relatório dos médicos de Manguinhos, sua argumentação de que a Cidade de Goiás representava o atraso e, por isso, Goiás todo assim o era, não teria sentido, uma vez que a então capital foi aprovada pela inspeção feita pelos dois médicos, que, entretanto, foram bem críticos em 
relação ao restante do Estado. Ora, considerar o relatório de 1916 seria o mesmo que considerar que as razões do atraso do Estado estavam enraizadas no próprio Estado e não era culpa de nenhuma cidade específica, muito menos da capital. Pedro Ludovico, então, desconsiderou o relatório, mas acatou as opiniões de dois ex-presidentes de Província, bem como utilizou como parâmetro para condenar a cidade, o Regulamento de Saúde Pública que ele mesmo criou, como veremos mais adiante.

Outrossim, na palestra de 1966, Pedro Ludovico inseriu o discurso de Miguel Lino de Morais, porém, não o faz em relação ao relatório dos médicos de Manguinhos, nem mesmo para dizer que eles estavam equivocados em suas percepções sobre a Cidade de Goiás. Entretanto, no início da sua fala, o médico e político vilaboense reconheceu o estado deplorável em que viviam os habitantes de Goiás, assemelhando ao relatório publicado cinquenta anos antes, principalmente ao enfocar que os homens do campo viviam: “anemiados, inutilizados pelas endemias rurais, mal podiam tirar da terra o sustento para si e suas famílias. Nenhum amparo do governo lhes vinha, quer médico, quer terapêutico. Vegetavam dia a dia, consumidos pela verminose e pela malária” (TEIXEIRA, 1966, p. 10).

\section{Diagnóstico}

O discurso urdido por Pedro Ludovico para justificar a urgência da mudança da capital, contempla, sobremaneira, os aspectos higiênico e sanitário. Assim, depois de ver o discurso histórico seletivo acerca da perenidade da doença da Cidade de Goiás, Pedro Ludovico se abstém de solicitar exames complementares, uma vez que o diagnóstico já se encontrava fechado. Um diagnóstico embasado histórica e cientificamente! Ademais, no contexto específico da década de 1930, mais precisamente na argumentação da construção de uma nova capital, sonhada por Pedro Ludovico para ser o oposto da sua terra natal, a Cidade de Goiás foi desconstruída política e historicamente. O interessante é que Pedro Ludovico, a todo o momento, no Relatório de 1933, reforçou o fato de que a antiga Vila Boa não atende os preceitos do Regulamento dos Serviços de Saúde Pública do Estado de $1931^{\text {iv }}$, ou seja, criado durante a sua gestão.

\footnotetext{
A mudança da capital, em 1933, tem a ver com a "criação" da Diretoria de Higiene e com o regulamento de 1931. É com base no saber médico que Pedro Ludovico, interventor federal, descaracteriza a antiga capital, Goiás, como cidade capaz de sediar o governo. Esse regulamento fornece, contra a cidade de Goiás, os principais argumentos, que se poderiam chamar "argumentos sanitários". E tendo por base esse saber médico, a nova capital, Goiânia, é fundada (CAMPOS, 1999, p. 232-233).
}

Sobre as residências, por exemplo, o Regulamento dos Serviços de Saúde Pública ressalta que todos os cômodos precisariam ter "porta ou janela abrindo diretamente para o 
exterior, por onde receba iluminação e insolação também diretas". As casas, por sua vez, deveriam guardar "distancias necessárias" uma das outras "para que se satisfaçam as condições convenientes de insolação". Ademais, "nenhum prédio poderá ser construído de modo que qualquer de suas paredes externas se apoie diretamente nas encostas de colinas, prédios vizinhos ou elevações de terreno". Os dormitórios, por fim, "deverão ter o seu piso banhado pelos raios solares, pelo menos durante duas horas no dia mais curto do ano" (GOIÁS apud TEIXEIRA, 1933, p. 112-113). Para se respeitar o respectivo Regulamento, a conclusão, ou diagnóstico, que Pedro Ludovico chegou versava que a situação da Cidade de Goiás era "insustentável”.

[...] as habitações da cidade de Goiaz [...] aberram todos os princípios de higiene e de todas as utilidades de conforto. $98 \%$ da população da capital dorme em alcovas bafientas, que nunca receberam sol e em que jamais entra luz ou ar diretamente do exterior. [...] Humidas e bafientas no inverno, quentes e abafadiças no verão, as peças íntimas da grande maioria das habitações desta capital, especialmente os quartos de dormir e as salas de trabalho incidem em cheio na proibição taxativa do mais tolerante regulamento de construções, insurgindo-se contra os mais rudimentares preceitos de higiene doméstica. Para as tornar mais distanciadas da habitação moderna e confortável do homem civilizado, faltamlhes ainda, ás habitações desta cidade, além de outros requisitos, instalações sanitárias. Enumeram-se a dedo, uma ou duas em cada rua, as casas dotadas desse elemento indispensável, a menos que se queira dar o nome de instalação sanitária a privadas sem esgoto e sem caixa de descarga, simples aberturas feitas no solo rochoso dos quintais. A casa habitada, trivial, de Goiaz, longe, pois, de abrandar a inclemência do clima, longe de proporcionar ao homem os meios de tornar mais fácil a vida e de se furtar á plenitude da ação entorpecente da elevada temperatura media local, como que colobora com ela no esforço de fazer inhabitavel a cidade de Goiaz (TEIXEIRA, 1933, p. 112 a 114).

É interessante ressaltar, mais uma vez, que o diagnóstico acima foi realizado com base em um documento elaborado pelo próprio governo do então Interventor Pedro Ludovico. Mesmo que o documento representasse o que havia de mais moderno para a medicina da época, a Cidade de Goiás não poderia ser condenada por sua arquitetura, em que os preceitos sanitários e higiênicos, quando da sua construção, eram outros ${ }^{\mathrm{v}}$. Outrossim, se o Interventor fosse usar tal documento para analisar a situação das cidades goianas do período, acabaria por condenar várias outras, cuja fundação remonta ao ciclo do ouro ${ }^{\text {vi }}$. Sua descrição da Cidade de Goiás se assemelha, de maneira impressionante, a várias cidades do Estado, principalmente quando ressalta ser a antiga Vila Boa um ajuntamento desordenado de "casas anti-higienicas e antiesteticas, apertando-se violentamente umas ás outras, dento de estreitíssima área acidentada, em torno da qual, sitiando-a, comprimindo-a, asfixiando-a quasi, se erguem morros e serras de todos os lados" (TEIXEIRA, 1933, p. 112).

Para além da arquitetura e da localização, o problema da falta de água e da rede de esgotos foram outros pontos aprofundados por Pedro Ludovico para desconstruir a Cidade 
de Goiás como capital do Estado. Sobre o primeiro, a falta de água, o Interventor observou que a água utilizada pela população tinha de ser buscada em duas fontes existentes na cidade: a Fonte da Carioca e o Chafariz do largo da Cadeia, construídas, respectivamente, em 1772 e 1778. Com isso, evidenciou o problema dos carregadores de água, formada, principalmente, por pessoas com problemas mentais. Essa "tendencia comum, verificável em muitas famílias goianas, de manter cada uma delas um bôbo - mentecapto, idiota, imbecil - para o serviço de transportes domésticos, especialmente o de água”. Dessa forma, existem "numerosas famílias que se beneficiam dos serviços desses desherdados da sorte, transformando-os em escravos irremissiveis, a troco dos restos de comida e de um canto para dormir, não raro entre os animais domésticos" (TEIXEIRA, 1933, p. 115). Esses mesmos argumentos foram reafirmados na palestra de 1966:

\begin{abstract}
Tôda a água consumida pela população era transportada na cabeça, em potes, e fornecida pelas duas únicas e pobres fontes existentes, as mesmas mandadas levantar, há 160 anos [...] Devido a perpétua escassez de água potável com que a população se via a braços durante o ano inteiro, especialmente à época da estiagem, havia verdadeira legião de carregadores para a baldeação do precioso líquido, os quais formavam extensa fila desde as primeiras horas da madrugada. É comum, nas localidades não providas de rêde de abastecimento de água, a perfuração de cisternas para consumo doméstico. Em Goiás, tal não era possível. A água é absolutamente impotável, dada a abundância de carbonato de cálcio que lhe adicionam as rochas calcáreas (TEIXEIRA, 1966, p. 16).
\end{abstract}

$\mathrm{E}$, mesmo se a água das cisternas fossem indicadas para o consumo, havia o problema da dificuldade em perfurá-las, já que, para isso, precisava utilizar muita dinamite, uma vez que a Cidade de Goiás "se assenta toda ela em terreno rochoso", que poderia comprometer a estrutura das casas, imagina, então, construir redes de esgoto: "E como póde uma cidade ser limpa, higiênica, habitável sem possuir um sistema de galerias subterrâneas para o escoamento dos detritos, águas servidas e materiais fecais?” (TEIXEIRA, 1933, p. 114).

Ao condenar a Cidade de Goiás como o contrário de "limpa", "higiênica" e “habitável", por meio da arquitetura, da água e da rede de esgotos, o discurso de Pedro Ludovico projeta a sua cidade imaginada. A cidade dos sonhos do Interventor. Ao desconstruir a antiga capital, o discurso ludoviquista constrói a cidade ideal, que seria, "o lócus privilegiado da saúde" (FREITAS, 1999, p. 240). Uma cidade que fosse simetricamente oposta à velha Goiás, e que serviria de inspiração para retirar todo o Estado do atraso, impulsionando, com isso, o tão desejado progresso.

\title{
Terapêutica
}

A cidade estava pensada, imaginada e desejada por Pedro Ludovico. Uma cidade 
ideal que não cabia dentro do fundo de vale a que a antiga Vila Boa estava perpetuamente condenada, cujos paredões da Serra Dourada delimitavam o seu crescimento tanto espacial quanto econômico, de acordo com o seu discurso. Embora a mudança da capital constasse na Constituição do Estado desde 1891, e que a Empresa de Força e Luz da capital fizesse prever em contrato, de 1918, que, se a capital mudasse, continuaria com os privilégios também na nova cidade, a resistência ao tratamento proposto por Pedro Ludovico foi grande. Defensores da antiga capital, principalmente entre os oposicionistas da Assembleia Estadual, condenavam a "campanha difamatória" que o governo de Pedro Ludovico fazia contra a Cidade de Goiás.

Os que defendiam que a Cidade de Goiás somente precisava de reformas estruturais para se modernizar, provavelmente estavam inspirados nas mudanças empreendidas em Paris por Georges-Eugène Haussmann (1809-1891), na segunda metade do século XIX, e em São Paulo e Rio de Janeiro, entre o final do século XIX e início do XX, em que "a elite governamental brasileira procurou sanear, embelezar e modernizar as principais cidades do país" (HAHNER, 1993, p. 165). A crença dos oposicionistas era de que, se foi possível fazer isso em outros lugares, também o seria na antiga Vila Boa. Porém, o discurso de Pedro Ludovico se inspirava em Belo Horizonte, criada ao final do século XIX para ser a capital mineira em substituição a Ouro Preto.

Uma vez que o principal argumento dos antimudancistas era que os investimentos empreendidos para a construção da nova capital poderiam tornar a Cidade de Goiás moderna e apta a continuar como centro de todo o Estado; Pedro Ludovico, por sua vez, cercou-se, no Relatório de 1933 e na palestra de 1966, também de argumentos contrários a essa posição. O então Interventor Federal, ao tecer um discurso que fundamentava o seu desejo, foi incisivo no diagnóstico da doença, e principalmente, no tratamento indicado: a completa omissão. O médico e o político se entrelaçaram de maneira inteligentemente e o paciente, uma vez diagnosticado com a doença do atraso, não caberia empreender nenhum esforço para tentar a cura, o progresso, porque o estado avançado da moléstia não possibilitava tal ação. Para se adequar, por exemplo, às exigências do Regulamento de Serviços de Saúde Pública, em relação à arquitetura das casas, deveria reconstruir a cidade, já que ela estava em desacordo com as posturas sanitárias do início da década de 1930. Ademais, a localização da Cidade de Goiás, cercada pela Serra Dourada, impedia o seu crescimento ordenado, com terrenos planos e que impossibilitava, também, a circulação do ar.

Noutro passo, a falta de água não seria facilmente resolvida, uma vez que o terreno não possibilitava sua canalização; por outro lado, o rio Vermelho sozinho não conseguiria 
suprir as necessidades da população, já que é um rio "sujeito a variações extremas". "Há anos em que, na seca, se reduz a um fio, a quase nada, e outros em que, na estação chuvosa, se centuplica, chegando a ameaçar as construções ribeirinhas" (TEIXEIRA, 1933, p. 115).

A esse argumento somam-se outros, como o fato de que "a cidade de Goiaz estaria até hoje ás escuras se o Estado, com os tributos dos demais municípios, não lhe pagasse a iluminação publica". Ademais, acaso contasse somente consigo, "a velha capital não teria promovido esse melhoramento, como por conta propria é quasi certo que não se promoverá nenhuma obra de vulto". No seu discurso, percebe-se a tentativa, a todo momento, de jogar o restante do Estado contra a Cidade de Goiás. Isso fica explícito não apenas quando afirma que as melhorias na antiga Vila Boa foram feitas com o dinheiro de todos os municípios, mas principalmente na conclusão de suas ideias, quando reitera que, com o dinheiro investido na iluminação da capital, "poderiam ter sido construídos 500 quilometros de bôas estradas de rodagem ou 26 grupos escolares" (TEIXEIRA, 1933, p. 122).

Em 1966, esse mesmo argumento foi retomado e aprofundado por Pedro Ludovico ao afirmar, por exemplo, que a capital desempenha "o papel de núcleo civilizador, de onde emana todo o influxo de progresso, que se estende sôbre todo o panorama do Estado, abrindo novos horizontes ao seu desenvolvimento". Nesse sentido, a Cidade de Goiás, "não estava em condições de desempenhar o papel importante de uma capital, geralmente considerada a cabeça do organismo estadual” (TEIXEIRA, 1966, p. 17).

O Interventor foi mais além quando afirmou que, de 1890 a 1932, deduzindo as casas que ruíram com o tempo, não houve nenhuma construção de novas moradias na Cidade de Goiás, e que a população decresceu em quase dois mil habitantes no mesmo período (TEIXEIRA, 1933, p. 122). Porque investir numa cidade estagnada, que não cresce? Era esse o ponto principal da argumentação ludoviquista para emitir o diagnóstico e a terapêutica, que selaram o destino de duas cidades e mudaram a história do Estado de Goiás.

\section{Considerações finais}

A obsessão de Pedro Ludovico em tirar da sua cidade natal o status de capital com a construção de uma nova ainda é um enigma para os historiadores. Não se sabe precisar o motivo real que o fez empreender tal iniciativa, somente se sabe que ela partiu unicamente dele. Embora evocasse vozes do passado para se justificar, Pedro Ludovico não escreveu uma linha sequer na defesa dessa ideia durante os anos em que esteve como editor do jornal oposicionista em Rio Verde, no início da sua vida pública.

Todavia, antes mesmo de Goiânia existir, ela já existia para Pedro Ludovico. Nos 
sonhos do Interventor, ela já estava traçada, arquitetada e pensada. Ela era tudo que a Cidade de Goiás nunca seria! Pressupomos que a nova capital seria a sua realização profissional e política. Profissional devido a sua formação médica, quando pôde colocar a mudança da capital como prioridade da sua administração, e fazê-la prosperar, com base na desconstrução da Cidade de Goiás, como lugar salubre, habitável e saudável. Embora recorresse aos mesmos argumentos dos que o precederam, Pedro Ludovico teceu a sua argumentação na oposição entre saúde e doença e projetou isso para além dos limites da Serra Dourada, enfeixando todo o Estado, jogando-o contra aquela que fora, no início do século XVIII, o berço de toda civilização goiana. E política, porque essa foi a plataforma que garantiu, não somente o grande período em que esteve no poder do Estado, como se transformou no seu principal legado. O médicofoi fundamental para o político, e este, por sua vez, fez de tudo para colocar em prática o tratamento indicado: a construção da nova capital goiana.

Em 1933, já na condição de Interventor Federal, Pedro Ludovico escreveu um relatório apresentado a Getúlio Vargas com o objetivo de fazer um diagnóstico do Estado nos três primeiros anos de governo, e justificar ao chefe do Executivo Federal sobre a importância da construção de uma nova capital para Goiás. Para isso, ele analisou, meticulosamente, a Cidade de Goiás, tal qual uma paciente, procedendo à anamnese, ao diagnóstico e à terapêutica. Aos desconstruir a cidade de Goiás, Pedro Ludovico construiu a sua cidade ideal, que, ainda, se encontrava no campo das ideias. Igualmente, 33 anos depois, em 1966, em sua palestra, o médico e político retomou os mesmos argumentos, não com o objetivo de justificar uma ideia, mas de atestar o quanto estava certo a sua iniciativa.

\section{Referências}

ABBAGNANO, Nicola. Dicionário de filosofia. São Paulo: Martins Fontes, 2000.

CAMPOS, Francisco Itami. Serviços de higiene, origem da saúde pública em Goiás. In: FREITAS, Lena Castello Branco Ferreira de (Org.). Saúde e doenças em Goiás: a medicina possível. Goiânia: Ed. da UFG. 1999, p. 223-238.

Mudança da capital: uma estratégia de poder. In: BOTELHO, Tarcísio Rodrigues (Org.) Goiânia: cidade pensada. Goiânia: Editora UFG, 2002, p.169-184.

CHAUL, Nars Fayad. A construção de Goiânia e a transferência da capital. Goiânia: Editora UFG. 1988. 
. Caminhos de Goiás: da construção da decadência aos limites da modernidade. Goiânia: Editora UFG. 2010.

FREITAS, Lena Castello Branco Ferreira de. Goiânia: lócus privilegiado da saúde. In: FREITAS, Lena Castello Branco Ferreira de. (Org.). Saúde e doenças em Goiás: a medicina possível. Goiânia: Editora UFG. 1999, p. 239-289.

HAHNER, June. Pobreza e Política: os pobres urbanos no Brasil (1870-1970). Brasília: Editora UNB. 1993.

LIMA, Nísia Trindade. Um sertão chamado Brasil: intelectuais e representação geográfica da identidade nacional. Rio de Janeiro: Revan, IUPERJ, UCAM. 1999.

LISBOA, Andreia Silva. O Brazil-Central e suas potencialidades na "Revista A Informação Goyana” (1917-1935). Dissertação (Mestrado em História). Universidade Federal de Goiás, Goiânia. 2009.

MACHADO, Maria Cristina Teixeira. Pedro Ludovico: um tempo, um carisma, uma história. Goiânia: Editora UFG. 1990.

MEDEIROS, Wilton de Araújo. Goiânia metrópole: sonho, vigília e despertar (1933/1973). Tese (Doutorado em História). Universidade Federal de Goiás, Goiânia. 2010.

MONTEIRO, Ofélia Sócrates do Nascimento. Como nasceu Goiânia. São Paulo: Empresa Gráfica da Revista dos Tribunais. 1938.

MORAES, Cristina de Cássia Pereira. O Hospital da Caridade São Pedro de Alcântara e os Trabalhadores na Cidade de Goiás - 1830-1860. In: FREITAS, Lena Castello Branco Ferreira de (Org.). Saúde e doenças em Goiás: a medicina possível. Goiânia: Ed. da UFG, 1999, p. 129-168.

NEIVA, Artur; PENA, Belisário. Viagem Científica pelo norte da Bahia, sudoeste de Pernambuco, sul do Piauí e norte e sul de Goiás. Edição Fac-Similar. Brasília: Senado Federal. 1999.

OUTHWAITE, William; BOTTOMORE, Tom. Dicionário do pensamento social do Século XX. Rio de Janeiro: Jorge Zahar. 1996. 
PALACÍN, Luís. Quatro tempos de ideologia em Goiás. Goiânia: Cerne. 1986.

PASSOS, Élder Camargo de. Do Gabinete Literário Goiano. In: Revista do Instituto Histórico e Geográfico de Goiás. Vol. n 10. Goiânia, Janeiro. 1982, p. 159-183.

POULOT, Dominique. Cultura, história, valores patrimoniais e museus. In: Vária História. Vol. 27, n. 46. Belo Horizonte, jul/dez 2011, p. 471-480.

SANDES, Noé Freire; CAIXETA, Vera Lúcia. O sertão remediado: o embate entre a elite goiana e o pensamento sanitarista, 1910-1920. In: História, Ciências, Saúde - Manguinhos. Rio de janeiro, v.23, n. 2, abr-jun. 2016, p. 397-410.

SILVA, Luiz Sérgio Duarte da. Progresso e sertão goiano: a espera. In: BOTELHO, Tarcísio Rodrigues (Org.) Goiânia: cidade pensada. Goiânia: Editora UFG. 2002, p. 129-152.

TEIXEIRA, Pedro Ludovico. Relatório apresentado ao Ex. ${ }^{m o} S{ }^{n r} D .^{r}$ Getúlio Vargas, d. d. Chefe do Governo Provisorio, e ao povo goiano, pelo dr. Pedro Ludovico Teixeira, Interventor Federal neste Estado. 1930-1933. Goiás. 1933.

Como e por que construí Goiânia. Brasília: Senado Federal, 1966.

A última entrevista de Pedro Ludovico Teixeira. In: Revista UFG. Ano XI, n. 6. Goiânia: Editora UFG. 2009.

Recebido em 29/07/2020

Aprovado em 01/09/2020

Publicado: $1 \% 01 / 2021$

\footnotetext{
${ }^{\text {i }}$ Doutor em História. Professor Adjunto da Faculdade de Ciências Sociais da Universidade Federal de Goiás. ii A caiação foi um tipo muito comum de pintura utilizada nas habitações principalmente na antiga Vila Boa de Goiás. Ela dava um efeito manchado às paredes e era muito fácil de fazer, posto que, nos arredores da vila, o solo era rico em calcário, transformado em cal virgem, o qual era misturado com água e usado como pintura.

iii Instituição cultural voltada para aquisição e circulação de livros, por meio de subscrições, instalada em 10 de abril de 1864, na Cidade de Goiás (PASSOS, 1982).

iv “Tendo por base o Decreto n. 714, de 19 de fevereiro de 1931, um novo regulamento do serviço de saúde é elaborado. Ele detalha os procedimentos a serem seguidos pela saúde pública em todo o estado. Tal como o regulamento de 1926, trata, inicialmente, da organização da Diretoria de Higiene, especificando serviços, cargos e atribuições. A diferença básica é que o regulamento de 1931 é mais longo e mais minucioso, com cerca de 1.100 artigos. O documento normatiza a casa, as ruas, a doença, as profissões, o trabalho, a escola, os alimentos, os hotéis e restaurantes, os hospitais, as farmácias, as barbearias, o lixo, o esgoto, a água, as igrejas e templos. Penetra e interfere em todos os recantos e meandros da vida da população" (CAMPOS, 1999, p. 234).
}

v A arquitetura da cidade de Goiás, nos séculos XVIII e XIX, “correspondiam plenamente aos conceitos médicos-higiênicos então vigorantes” (MORAES, 1999, p. 132). 


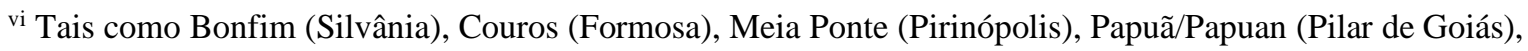
Porto Real (Porto Nacional), São José de Mossâmedes (Mossâmedes), São José do Tocantins (Niquelândia), Santa Luzia (Luziânia), dentre outros. 